\title{
A case of ceftriaxone-induced biliary pseudolithiasis in childhood
}

\author{
Sarathchandra J C ${ }^{1}$, Perera $\mathbf{R} \mathbf{M} \mathbf{S}^{2}$, Jayakody $\mathbf{R} \mathbf{L}^{3}$ \\ Sri Lanka Journal of Child Health, 2006; 35: 72
}

(Key words: ceftriaxone induced biliary pseudolithiasis, child)

\section{Introduction}

Gall stones are uncommon in children, and when found one has to suspect an underlying predisposing cause. In Sri Lanka, one has to suspect underlying haemolytic anaemia. In this case report we highlight an iatrogenic factor which is known to produce a condition simulating gall stones. Ceftriaxone-induced reversible precipitation of ceftriaxone-calcium in the gall bladder is known to mimic cholelithiasis and is termed biliary pseudolithiasis or reversible cholelithiasis ${ }^{1}$.

\section{Case report}

A 10 year old boy was admitted to the ward with symptoms of fever and vomiting of 5 days duration and loose stools for 1 day. On the third day in hospital he complained of severe headache and it was associated with neck stiffness. CSF analysis showed evidence of pyogenic meningitis. He was treated with high dose of ceftriaxone sodium intravenously $(100 \mathrm{mg} / \mathrm{kg} /$ day) for one week. After 5 days of treatment he complained of abdominal pain and had a tender lump in the right hypochondrium. Ultrasound scan of the abdomen showed multiple small gall stones. Ceftriaxone was discontinued and the boy was managed conservatively. A repeat scan done 3 weeks later showed complete resolution of the stones. An underlying haemolytic condition was excluded.

\section{Discussion}

Using abdominal ultrasonography, biliary sludge or pseudolithiasis was found in about $40 \%$ of severely ill children being treated with high doses of ceftriaxone ${ }^{2}$. The sludge has been identified as a calcium salt of ceftriaxone ${ }^{3}$. Patients are often asymptomatic and the

${ }^{1}$ Consultant Paediatrician, ${ }^{2}$ Senior House Officer, Colombo South Teaching Hospital, Kalubowila, ${ }^{3}$ Professor of Pharmacology, Faculty of Medicine, Colombo

(Received on 14 October 2005. Accepted on 12 December 2005) sludge usually dissolves once ceftriaxone is discontinued $^{2}$. A bile-duct stone composed of ceftriaxone occurred with high-dose ceftriaxone in a child $^{4}$. We are unaware of reports of this condition appearing with other commonly used cephalosporins. As ceftriaxone is commonly used in Sri Lankan hospitals clinicians should be aware of it.

\section{References}

1. Herek O, Sarioglu A, Kocer N, Tiryaki A. Akkemik B. Biliary pseudolithiasis in childhood; a case report. European Journal of Paediatric Surgery 1999; 9(5):337-9.

2. Schaad UB. Reversible ceftriaxone-associated biliary pseudolithiasis in children. Lancet 1988; ii: 165 .

3. Park HZ. Ceftriaxone-associated gallbladder sludge: identification of calcium-ceftriaxone salt as a major component of gallbladder precipitate. Gastroenterology 1991; 100: 1665-70.

4. Robertson FM. Ceftriaxone choledocholithiasis. Pediatrics 1996; 1996; 98: 133-5. 